\title{
Fetal interventions for congenital renal anomalies
}

\author{
Ahmer Irfan, Elizabeth O’Hare, Eric Jelin \\ Department of Surgery, Division of Pediatric Surgery, Johns Hopkins Hospital, Baltimore, MD, USA \\ Contributions: (I) Conception and design: A Irfan, E Jelin; (II) Administrative support: None; (III) Provision of study materials or patients: None; \\ (IV) Collection and assembly of data: None; (V) Data analysis and interpretation: None; (VI) Manuscript writing: All authors; (VII) Final approval of \\ manuscript: All authors. \\ Correspondence to: Eric Jelin, MD. Department of Surgery, Division of Pediatric Surgery, Johns Hopkins School of Medicine, 1800 Orleans St, \\ Baltimore, MD 21287, USA. Email: ejelin1@jhmi.edu.
}

\begin{abstract}
Congenital abnormalities of the kidney and urinary tract (CAKUT) represent $20 \%$ of prenatally diagnosed congenital abnormalities. Although the majority of these abnormalities do not require intervention either pre or postnatally, there is a subset of patients whose disease is so severe that it may warrant intervention prior to delivery to prevent morbidity and mortality. These cases consist of patients with moderate lower urinary tract obstruction (LUTO) in which vesicocentesis, shunting or cystoscopy are options and patients with early pregnancy renal anhydramnios (EPRA) in whom amnioinfusion therapy may be an option. The main causes of EPRA are congenital bilateral renal agenesis (CoBRA), cystic kidney disease (CKD) and severe LUTO. Untreated, EPRA is universally fatal secondary to anhydramnios induced pulmonary hypoplasia. The evidence regarding therapy for LUTO is limited and the stopped early PLUTO (Percutaneous Shunting in Lower Urinary Tract Obstruction) trial was unable to provide definitive answers about patient selection. Evidence for EPRA therapy is also scant. Serial amnioinfusions have shown promise in cases of EPRA due to CoBRA or renal failure and this treatment modality forms the basis of the ongoing NIH funded RAFT (Renal Anhydramnios Fetal Therapy) trial. At present, there is consensus that treatment for EPRA should only occur in the setting of a clinical trial.
\end{abstract}

Keywords: Bilateral renal agenesis; anhydramnios; vesicoamniotic shunting, renal anhydramnios fetal therapy (RAFT)

Submitted Apr 08, 2020. Accepted for publication Oct 16, 2020.

doi: $10.21037 /$ tp-2020-fs-05

View this article at: http://dx.doi.org/10.21037/tp-2020-fs-05

\section{Introduction}

Congenital abnormalities of the kidney and urinary tract (CAKUT) tract complicate 1-4 per 1,000 pregnancies and represent up to $20 \%$ of prenatally diagnosed congenital anomalies (1,2). Morbidity and mortality of diseases in this group depends on the severity of oligohydramnios secondary to impaired or absent renal function. Urine produced by the fetal kidneys constitutes $90 \%$ of amniotic fluid by 16 weeks GA, so urine output is necessary for maintaining amniotic fluid volume. When this cycle is disrupted, its effects can be disastrous for the fetus and therefore treatment is crucial. In addition to preservation of amniotic fluid volume, early intervention can be important in maintaining adequate renal function, to prevent the need for renal replacement therapy (RRT) in the neonatal period.

Sufficient pulmonary development relies on amniotic fluid, since amniotic fluid maintains tracheobronchial essential airway pressure dynamics in the fetal lung. When amniotic fluid is low or absent, lung fluid escapes out of the airway and pulmonary development decreases or may cease altogether. Pregnancies complicated by anhydramnios secondary to severe CAKUT prior to 22 weeks GA constitute early pregnancy renal anhydramnios (EPRA) (3). The main etiologies of EPRA are congenital bilateral renal agenesis (CoBRA), cystic kidney disease (CKD), and severe lower urinary tract obstruction (LUTO) (4-6). EPRA is considered universally fatal due to pulmonary insufficiency 
at birth. Benign genitourinary (GU) anomalies (including unilateral renal agenesis, mild urinary tract dilation, pelvic kidneys, and horseshoe kidneys) are common and typically do not cause renal failure, oligo- or anhydramnios and as such are not the focus of this review.

Although peri- and postnatal intervention has improved for treating renal anomalies, fetal intervention may be considered for a subset of patients to preserve renal function or restore amniotic fluid volume in order to rescue pulmonary development. Untreated, these conditions cause irreparable harm and therefore may warrant consideration of fetal intervention.

\section{Diagnosis}

A complete ultrasound is critical in the diagnosis of CAKUT to allow any additional fetal anatomical variations to be identified. As its use has become more commonplace, the prenatal diagnosis of these conditions has allowed for earlier intervention (7). Ultrasound diagnosis can be followed by invasive testing such as amniocentesis, chorionic villous sampling or vesicocentesis. In the setting of LUTO, vesicocentesis, which involves percutaneous drainage of the fetal bladder under ultrasound guidance (8), can be used to assess bladder filling as well as measure electrolytes and beta2microglobulin, both of which can be used for prognostication (9). Poor bladder filling in these situations suggests that the fetus is a poor candidate for LUTO-specific renal preserving interventions. Further information in CAKUT can also be ascertained from a diagnostic amnioinfusion (10) which can be used to confirm intact membranes (as premature preterm rupture of membranes can be a cause of oligohydramnios at this GA), as well as allow for a more detailed sonographic evaluation, both for the absence/presence of renal tissue as well as other anomalies. The presence of other significant fetal anomalies outside of the urinary tract may indicate a syndromic etiology of disease.

\section{Lower urinary tract obstruction (LUTO)}

Obstructive uropathies are the most common type of CAKUT. The three levels of obstruction can be categorized as upper (ureteropelvic junction), middle (ureterovesical junction) or lower (urethral) $(11,12)$. Upper and mid-level obstructions are more commonly unilateral and therefore associated with less severe consequences. However, bilateral or lower level obstruction can lead to a poor prognosis.
Fetal urinary obstruction can lead to renal dysfunction, which can be associated with a $30 \%$ lifetime risk of renal failure (13). In addition, a third of children who progress beyond the neonatal period will have bladder dysfunction (urinary retention, incontinence or both) due to inadequate bladder cycling as a fetus (14). At the most extreme end of the disease, severe disease can lead to anhydramnios which can be ultimately fatal due to pulmonary hypoplasia.

LUTO, also referred to as bladder outlet obstruction, develops secondary to a mechanical obstruction at the level of the urethra. The most common causes of this are posterior urethral valves (PUV) and urethral stenosis or atresia (UA) (15). PUV is the most common cause of LUTO in males, while UA is the most common cause in females (16); as PUV is a more common etiology the incidence of LUTO is higher in males overall (17). The outcomes of untreated LUTO are poor, with mortality up to $90 \%$. Of the survivors, renal failure is common, with up to half the patients requiring eventual dialysis or transplantation $(12,18)$.

Prenatal ultrasonography is a preferred initial test for the diagnosis of LUTO with excellent sensitivity (95\%) and specificity (80\%) (15). The common ultrasound findings are a dilated bladder with a thick wall, bilateral hydroureters, and hydronephrosis, often associated with oligohydramnios or anyhydramnios. Severe LUTO can present as firsttrimester megacystis (defined by a longitudinal bladder diameter of $>7 \mathrm{~mm}$ ), with the most severe form (diameter $>15 \mathrm{~mm})$ associated with a high $(10 \%)$ incidence of chromosomal abnormalities (19). The characteristic 'keyhole sign' (Figure 1) is commonly seen and represents a dilated posterior urethra, though this does not further delineate the underlying etiology of LUTO (20). Fetal MRI may be considered in addition to ultrasonography when severe oligohydramnios is present. Whereas MRI may provide more detailed information regarding the urethral obstruction and other anomalies, it is also generally not capable of elucidating the underlying LUTO etiology (21).

Although there have been reports of spontaneous resolution of LUTO and normalization of amniotic fluid volumes (22), the majority of patients $(90 \%)$ do not experience this course. Therefore, the need for intervention is still vital in improving outcomes. Current treatment options for moderate LUTO include: vesicocentesis, vescioamniotic shunting, and fetal cystoscopy (12). The purpose of these interventions is both to preserve amniotic fluid volume and to maintain renal function. As with all surgical interventions, patient selection is critical. While minimally 


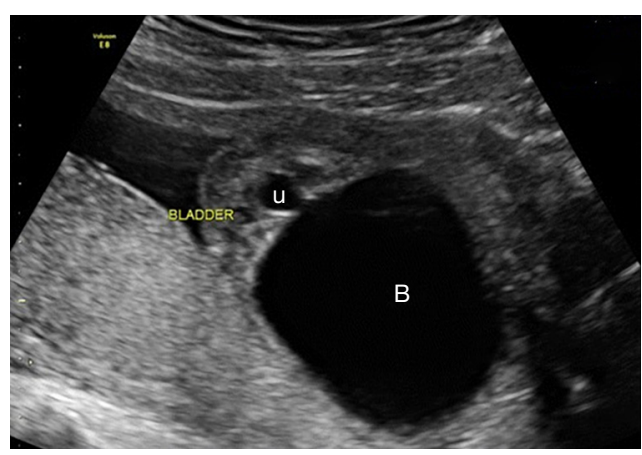

Figure 1 Ultrasound of fetal bladder with classic "keyhole sign" (8).

invasive in-utero procedures carry less morbidity than open interventions, there are still risks to both the pregnant woman and her fetus, including fetal demise, preterm labor, preterm rupture of the membranes (PROM) and infections (12). Therefore, well-established criterion should be discussed prior to intervention.

Criterion that may determine suitability for intervention in LUTO are (12): (I) fetus with normal karyotype without any other associated anomaly; (II) ultrasound findings of bladder obstruction; (III) the presence of oligohydramnios or anyhydramnios; (IV) 'favorable' urine analysis [defined as urinary sodium $<100 \mathrm{mEq} / \mathrm{L}$, chloride $<90 \mathrm{mEq} / \mathrm{L}$, osmolarity $<200 \mathrm{mOsm} / \mathrm{L}$ and $\beta 2$-microglobulin $<6 \mathrm{mg} / \mathrm{L}$ (23)]. The process and efficacy of these therapeutic options will be discussed in more detail in the following section.

\section{Therapeutic options}

The rationale for in-utero therapy for LUTO is to decompress the renal tract to prevent renal impairment necessitating dialysis and/or transplantation. In cases where anhydramnios is present, it allows the restoration of amniotic fluid volume to prevent lung hypoplasia (12). In addition, in very severe forms of LUTO, there may be no bladder filling (anuria), so these fetuses would not be candidates for any of the below therapies and in the past have only been offered palliative care and termination of pregnancy. But, these fetuses may benefit from serial amnioinfusions as are being done in the RAFT (Renal Anhydramnios Fetal Therapy) trial (24).

\section{Vesicocentesis}

This is the simplest of the procedures and involves percutaneous access of the bladder with a needle and aspiration of urine. Some studies show vesicocentesis can be effective in relieving urethral obstruction $(25,26)$ though other studies have refuted this finding $(19,27,28)$. In addition, in order to obtain sufficient decompression, vesicocentesis must be performed several times per week, which significantly increases the risks of intervention. At present, vesicocentesis is primarily used as a diagnostic tool. It should be noted that at least three vesicocenteses are recommended to adequately analyze renal function since initial samples may only represent stagnant urine that has been stuck in the fetal bladder.

\section{Vesico-amniotic shunting}

The use of a vesico-amniotic shunt is the most common method used to relieve urinary tract obstruction. This method involves the placement of a pigtail catheter under ultrasound guidance, with the proximal end inside the fetal bladder (ideally in the distal portion to prevent dislodgment during decompression) and the distal end in the amniotic cavity. This procedure can be very difficult in cases of severe oligohydramnios and therefore may require a preprocedural amnioinfusion.

The evidence on the efficacy of vesico-amniotic shunting is unclear (29) though one systematic review showed that prenatal bladder drainage appears to improve survival in cases of LUTO, with continued risk of poor postnatal renal function (30). In the absence of high-quality data, the multicentered PLUTO trial (31) was launched to determine the role of fetal vesicoamniotic shunting in moderate/severe LUTO. Unfortunately, the trial was stopped early due to poor recruitment (20\%) (32). The results of the trial showed that shunted fetuses had a higher chance of neonatal survival than non-shunted fetuses $(9 / 15$ vs. 3/16; RR $3 \cdot 20$, $\mathrm{P}=0.03$ ). All deaths in the early neonatal period were caused by pulmonary hypoplasia. It is also important to note that only two patients in the shunted group had normal renal function at 2 years. Therefore the authors concluded that while the survival was higher in shunted fetuses, the chance of progressing with normal renal function was very low irrespective of shunting (33). However, the trial's inclusion criteria, which included the physician being uncertain of the optimum management and its early conclusion, make its findings difficult to interpret and potentially not representative of the entire LUTO population.

\section{Fetal cystoscopy}

Fetal cystoscopy can also be used for diagnosis and potential treatment of the underlying etiology of LUTO. This procedure is generally performed under maternal 


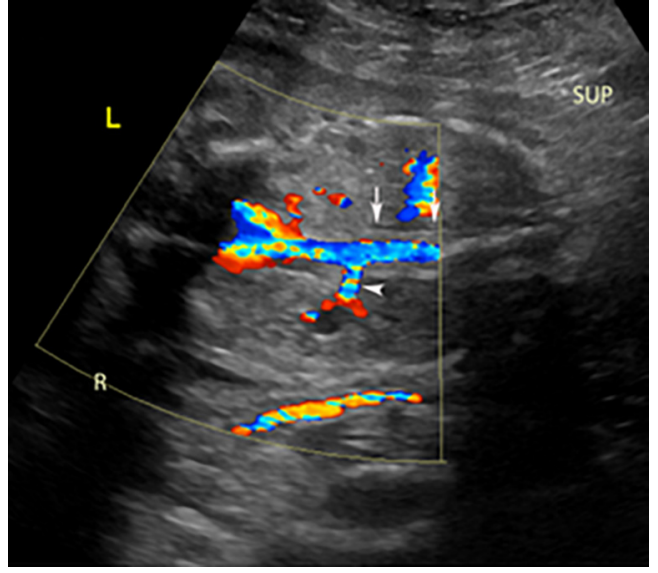

Figure 2 Coronal View color doppler showing left sided renal agenesis with a "lying down" left adrenal gland (arrow) (37).

epidural anesthesia with fetal anesthesia involving direct injection into the umbilical vein or into the subcutaneous space. Under US guidance, a curved $2.2 \mathrm{~mm}$ trochar is inserted into the upper portion of the fetal bladder through the maternal abdomen, uterine wall, and amniotic cavity taking care to avoid the placenta. A 1.0 or $1.3 \mathrm{~mm}$ fetoscope is passed through the sheath and the bladder mucosa examined. The scope is then advanced towards the bladder neck and if a membrane-like obstruction of the urethral lumen is seen (which can be confirmed by saline injection through the membrane), then diagnosis of PUV can be made and intervention can be undertaken (22). There are several methods to perforate PUV, including hydroablation, guide-wire perforation or laser fulguration. Following the disruption of the valves, urine is able to flow through the patent urethra. This can be confirmed by power Doppler showing passage of fluid through the patent urethra into the amniotic cavity. However, if the obstruction is nonmembranous then it likely due to UA and intervention should not be undertaken (22). The complications of fetal cystoscopy are similar to other procedures that involve penetration of the uterine cavity including premature rupture of membranes, preterm labor, placental abruption, chorioamnionitis, and uterine rupture (24), however a risk specific to fetal cystoscopy is the development of urinary ascites (which may require prenatal aspiration) (34). Ablation of valves in utero can also result in a fistulae between the urinary tract and the GI tract and skin (22).

The diagnostic sensitivity of fetal cystoscopy is excellent, detecting the etiology of LUTO in $>90 \%$ of cases $(22,34-36)$. The data for interventional outcomes with this method for PUV is limited, with the largest study showing modest long-term survival (54\%) but with adequate preserved normal renal function in two thirds of the infants (36). When compared to vesico-amniotic shunting, both showed improved 6-month survival, however fetal cystoscopy was shown to be more effective at preventing renal impairment (17).

\section{Early pregnancy renal anhydramnios (EPRA)}

EPRA encompasses the most severe form of CAKUT that results in fetal anhydramnios by 22 weeks gestation (3). EPRA is thought to be universally fatal secondary to pulmonary hypoplasia and affects 1 in 2000 pregnancies. The main etiologies are congenital bilateral renal agenesis (CoBRA), cystic kidney disease (CKD), and severe LUTO (4-6). In these patients, it is crucial to evaluate the entire genitourinary $(\mathrm{GU})$ tract, including the urethra, bladder, ureters and kidneys, to identify or rule out a specific anomalies that may have renal, urologic or genetic significance (3).

\section{Congenital bilateral renal agenesis (CoBRA)}

CoBRA, or the absence of both kidneys, is thought to be universally fatal if untreated due to anhydramnios since no fetal urine is produced. CoBRA is suspected when neither kidney is visualised on ultrasound. A classic ultrasound finding is known as the "lying down adrenal sign" (Figure 2). In typical anatomy, the normal adrenals appear as a "Y-shape" on ultrasound, but in the absence of the kidney the adrenal gland will appear linear (38).

Prior to a case report in 2014, there were no documented survivors with bilateral renal agenesis beyond the neonatal period. In 1994, there was a case report that utilised serial amnioinfusions in a patient with CoBRA who was born with no pulmonary hypoplasia. The patient was placed on peritoneal dialysis for RRT, but this was unsuccessful and the patient died at the age of 23 days (37). Due to this prognosis, aggressive obstetric or neonatal management was not offered to these patients as the pulmonary hypoplasia and available RRT was not compatible with prolonged extrauterine life (39). Current treatment options for CoBRA patients will be discussed in the amnioinfusions section.

\section{Cystic kidney disease (CKD)}

CKD comprises a group of renal parenchymal disorders 
which include autosomal recessive polycystic kidney disease (ARPKD), autosomal dominant polycystic kidney disease (ADPKD), and multicystic dysplastic kidney disease (MCDK). ADPKD most commonly manifests in adulthood with enlarged cystic kidneys and will not be discussed in this review.

MCDK consists of multiple noncommunicating cysts of various sizes separated by dysplastic renal parenchyma. Primitive urine filled nephrons are the basis of the multiple cysts, which are seen initially at the periphery of the kidney. The affected kidney is non-functional and frequently undergoes involution when the cysts shrink from absence of urine production. Ultrasound is used for diagnosis and shows multiple anechoic cysts of variable sizes replacing the normal renal parenchyma. This disease can present unilaterally or bilaterally with the unilateral form having a far superior prognosis (40) as demonstrated by a study that showed that no patients with bilateral MCDK and oligo/ anhydramnios survived beyond the neonatal period (4).

ARPKD is characterized by nonobstructive dilatation or ectasia of the collecting tubules located in the renal medulla. The severity of the renal disease is proportional to the percentage of nephrons affected by cysts (41). The cysts can be discrete and sometimes too small to visualize. The presence of macrocysts $(>10 \mathrm{~cm})$ is used to differentiate MCDK from ARPKD. In patients with ARPKD, the lungs may appear proportionally small due to abdominal distention and pulmonary hypoplasia. However, in nonEPRA patients, the large kidney size may lead to severe respiratory compromise even without pulmonary hypoplasia from anhydramnios (42).

\section{Fetal lung development}

The major cause of mortality in EPRA is lung hypoplasia, the mechanism of which is compromise of intra-uterine and tracheobronchial fluid dynamics. The importance of lung liquid volume in the normal development of fetal lungs has been demonstrated in several animal models (43). In sheep models it was shown that this lung liquid was produced by the pulmonary epithelium (as opposed to entirely swallowed amniotic fluid as was once perceived) and maintenance of this volume and pressure in the intrapulmonary space impacts lung growth $(43,44)$. The lung fluid is thought to act as an "internal splint" that is kept in place by a closed glottis. Increasing the volume/pressure in the tracheobronchial tree causes increased lung growth, whereas a decrease in lung fluid volume/pressure (through external drainage) leads to pulmonary hypoplasia $(45,46)$.

The upper airway is the key regulator of this fluid dynamic, controlling the movement of lung fluid from intrapulmonary to intraamniotic. Alteration in the upper airway can lead to an alteration in fluid shifts, shown by disruption of the recurrent laryngeal nerve leading to an increased efflux of lung fluid (47). In a patient with EPRA and a normal upper airway, lung fluid is allowed to escape the tracheobronchial tree into the amniotic sac during fetal glottis opening due to pressure changes. This results in depressurization of the fetal tracheobronchial tree and loss of lung liquid which limits fetal lung growth $(48,49)$.

The importance of upper airway regulation has been demonstrated in cases where intrauterine airway occlusion has resulted in non-hypoplastic lungs despite the presence of other anatomic abnormalities that would normally have led to pulmonary hypoplasia. A case of an infant with bilateral renal agenesis and concurrent laryngeal atresia was found to have enlarged lungs (50). Another case demonstrated an infant with congenital diaphragmatic hernia $(\mathrm{CDH})$ and a sequestered left lower accessory lobe. The normal lung was hypoplastic as expected in $\mathrm{CDH}$ but the sequestered lobe was expanded and fluid filled (51). With these cases and the evidence of several animal studies showing the effects of tracheal ligation on increasing lung growth (45,52-54), tracheal occlusion has been pursued as a treatment option to improve pulmonary hypoplasia. The efficacy of this is currently under investigation in $\mathrm{CDH}$ (55). The details of this therapy and trial are outside the scope of this review.

\section{Anhydramnios and amnioinfusions}

The regulation of lung fluid is controlled by the upper airway; however, the direction of flow is related to amniotic fluid volumes. In oligo- or anhydramniotic patients, the pressure changes between intrapulmonary and intraamniotic allows fluid to escape when the glottis is open. With no production of amniotic fluid in patients with EPRA, this cycle continues, and lung hypoplasia occurs. Along with pulmonary hypoplasia, anhydramnios is also associated with increased risks of other potentially devastating complications including acute umbilical cord compression, fetal asphyxia and severe skeletal structural abnormalities (56).

The causative link of amniotic fluid levels and functional lung growth has been demonstrated by a set of discordant monoamniotic twin fetuses. One fetus had CoBRA (and therefore no urine production), but shared a normal 
amniotic sac with his cotwin; he subsequently had normal respiratory function at birth (57). This link has driven investigators to attempt serial amnioinfusions to increase amniotic fluid volume in the management of patients with EPRA associated disease to prevent this lung fluid loss and the subsequent development of pulmonary hypoplasia (58). Some case reports have been published utilizing serial amnioinfusions in cases of EPRA and have shown improved pulmonary function in these patients post-delivery $(58,59)$. Patients with isolated CoBRA may be eligible for inclusion in the RAFT trial, with one of the study groups in the trial focusing exclusively on patients with this etiology of EPRA.

Patients with bilateral multicystic dysplastic kidney (MCDK) and early severe LUTO may also fall under the umbrella of EPRA and suffer its lethal complications. Therefore, this subset of patients is eligible for screening as a second independent group in the RAFT trial (24). As is hypothesized for CoBRA patients, serial amnioinfusions may enable sufficient pulmonary development, to allow survival beyond the neonatal period. Amnioinfusion for autosomal recessive polycysic kidney disease (ARPKD) is controversial at present as ARPKD can cause pulmonary hypoplasia through various etiologies. Some patients with ARPKD may present with EPRA and secondary pulmonary hypoplasia. However, a subset of (non-EPRA) ARPKD patients can also present with respiratory compromise, due to compressive effects of the large kidney. Patients with classic ARPKD detected on ultrasound are not currently eligible for therapy in the RAFT trial $(3,24)$.

\section{Renal replacement therapy (RRT)}

If pulmonary development is restored by amnioinfusions, postnatal RRT will be necessary to treat the patient's end stage renal disease (ESRD). Over the past two decades, there has been an expansion and improvement in neonatal RRT (especially with respect to automated peritoneal dialysis) with a $80 \% 5$-year survival rate (60). Patients who initiate dialysis as a neonate are significantly more likely to undergo peritoneal dialysis (as opposed to hemodialysis). While there remains significant concern about RRT in neonates, there has been evidence to show that neonatal dialysis is fairly successful therapy. Early dialysis initiation (within the $1^{\text {st }}$ month of life compared to 1-24 months) does not statistically impact patient mortality or the likelihood of termination of dialysis (reasons for which include renal transplant or change of dialysis modality or recovery) (60). In patients with CAKUT requiring amnioinfusions, the likelihood of recovery is zero and the role of dialysis is to act as a bridge to transplantation which is the optimal RRT modality, as it reduces long-term morbidity and mortality and optimizes growth and development in a child with ESRD $(60,61)$. The aim is to transplant the patient when he or she reaches 2 years of age or 10 kilograms with $80 \%$ of neonatal dialysis patients able to make the transition by the age of $5(58,60,62)$. In CoBRA patients, complete reconstructive surgery of the urinary tract may be necessary since there are likely to be significant defects in the urinary tract. However, there is no data for transplantation outcomes in these patients as historically this disease was lethal, and patients did not survive to RRT.

\section{Amnioinfusion trials}

In addition to EPRA, other human diseases can result in oligohydramnios and subsequent pulmonary hypoplasia, such as preterm premature rupture of membranes (PPROM). The use of serial amnioinfusions to restore pulmonary development in such cases has also been investigated. A systematic review showed an improvement in outcomes following serial amnioinfusions in observational studies, though this was not replicated in the included randomised control trials (RCTs) (63). A criticism was that RCTs were carried out in women who were between 24 and 36 weeks gestational age (GA) and that the critical time for lung development (and therefore requirement for adequate amniotic fluid) is between 16 and 24 weeks GA (64). A pilot study on serial amnioinfusions in PPROM between 16and 24-week GA suggested that amnioinfusions may lead to better outcomes in these patients. Of the patients in the amnioinfusion group, $14 \%$ were healthy at age 2, compared to $0 \%$ of the expectant group. Whilst these results were promising, the study was small and underpowered and statistically significant conclusions cannot be made; this is acknowledged in the study and the need for a high powered RCT is stressed.

\section{The RAFT trial}

The experience from successful case reports led to a hypothesis that $25 \%$ of patients who receive serial amnioinfusions will develop functional neonatal lungs that permit survival (65). With no current management options for these patients and a 100\% mortality, the RAFT Trial was developed (24). This is an ongoing multicentre R01 funded (R01HD100540) trial designed to prospectively 
evaluate serial amnioinfusions for EPRA. There was a need to thoroughly investigate this intervention early in its development, as its routine use could have led to the same issues that led to the early closure of the PLUTO trial. Due to the nature of the condition, a national ethics symposium was convened to navigate the complex issues that surrounded this trial to provide an ethically sound protocol. The issues included but were not limited to: autonomy, medical futility, informed consent, financial risk and societal cost (66). It was also universally agreed, both by the ethical symposium and an NIH workshop focused on similar issues $(56,66)$, that serial amnioinfusions should not be offered as a treatment modality outside of an IRB approved research study. In this background the primary aims of the RAFT trial are to determine the safety, feasibility and preliminary efficacy of serial amnioinfusions. Participants in the trial will not be randomised because there is no realistic hope of neonatal survival in the setting of expectant management (24). Nonetheless patients who do not opt for termination and are willing to be followed at a RAFT center but do not wish to undergo amnioinfusions are still offered participation in the trial. Recruitment in this group may be very challenging and the trial is therefore powered based of the intervention group. Nonetheless the expectant management may provide critical insights into the relatively understudied in utero and possibly postnatal natural history of EPRA.

A multi-disciplinary approach is utilised when evaluating patients for the RAFT trial with involvement of specialists from maternal fetal medicine, pediatric surgery, genetic counseling, nephrology, neonatology, and social work (66). Serial amnioinfusions are not without risk and patients must be appropriately counselled and consented. These risks include premature rupture of membranes, preterm labor, placental abruption, chorioamnionitis, and uterine rupture (24) as well as post-natal challenges including the need for dialysis or renal transplant and the complications that are associated with these interventions (3).

\section{Further innovation in fetal therapies}

The design and execution of fetal renal treatment trials can present with many obstacles and challenges, as was shown in the PLUTO trial. Fetal renal disorders that may benefit from fetal interventions are rare. Moreover, many of these cases may go undetected prenatally (67). Recruitment may also be challenging since, historically, some of these conditions such as EPRA were considered universally lethal (32).

When a new therapy enters clinical practice without prospective assessment, it allows clinicians to develop their own biases, often on the basis of small observational studies. This leads to a loss of clinical equipoise which can in turn lead to poor recruitment in prospective trials, as was the case in the PLUTO trial. While the trial investigators attempted to circumnavigate this, by allowing treatment outside of the trial and only including patients in whom the physician was uncertain of optimum management, it led to further recruitment issues and the potential for a selection bias. As serial amnioinfusions have not yet found use outside of clinical trials, the hope is that the RAFT trial will not run into this pitfall and its results and recruitment will be free from these biases.

A third challenge in the creation of a successful fetal therapy trial is the need for long-term follow-up data. This can be labor-intensive and costly, though necessary to truly inform parents about the risks and benefits of these fetal procedures. The PLUTO trial followed its patients for two years, though some would argue that these children should have be followed as far as school-age to truly assess longterm renal function and neurodevelopment (32). The RAFT trial has partnered with NAPRTCS (North American Pediatric Renal Trials and Collaborative Studies) registry to ensure long-term outcomes of surviving patients and their families are evaluated. This registry captures nearly all pediatric patients on dialysis and encompasses nearly 100 centers around the United States.

\section{Innovations in renal disease}

With respect to innovation in patients with CAKUT, the results of the RAFT trial are eagerly awaited to assess if these patients can survive beyond the neonatal period. Should there be a proven benefit to amnioinfusions, the modality with which to deliver the treatment will be an important consideration. Currently, amnioinfusions are given intermittently through a transabdominal approach. In studies in PPROM this approach was found to be insufficient (68) and continuous amnioinfusion therapies were developed for this patient group. There have been reports of implantation of a subcutaneous port with an intraamniotic catheter to infuse fluid (69) or use of an indwelling epidural catheter in the amniotic space (70) in patients with PPROM. The use of a subcutaneous amniotic port (amnioport) has also been studied in EPRA patients with promising outcomes (71). It is hoped that the use 
of indwelling devices for amnioinfusions reduces the risk associated with repeated puncture which include premature rupture of membranes, preterm labor, placental abruption, chorioamnionitis, and uterine rupture (24). However, the use of these devices in clinical practice still has some hurdles to clear. Firstly, the successful use of amnioinfusions has to be determined by the RAFT trial. Following this, the safety and efficacy of the amnioport has to be appropriately studied; both in animals and then progressing into controlled IRB-approved FDA approved human trials. The amnioport approach may increase ease of amnioinfusions and improve fetal outcomes but this has to be weighed against increased maternal risks of more invasive fetal surgery.

Although transplantation is the ideal form of RRT for neonates, it comes with its own set of risks including immunosuppression, rejection and graft failure. There continues to be progress made with graft matching and minimization of immunosuppression. While there have been cases of patients with long term survival and graft function following kidney transplants without immunosuppression (72), the risks of graft loss and dysfunction are thought to be very high with this approach. However, in order to broach the potential for organ transplantation without immunosuppression, the concept of induced immune tolerance has been increasingly studied (73). This phenomenon, provoked through mixed chimerism, is when the lymphohematopoietic system of the recipient comprises a mixture of host and donor cells. This has been achieved through bone marrow (BM) or mobilized peripheral blood stem cell transplantation (74). In combination with total lymphoid irradiation and thymic suppression, it has led to successful transplants without the use of immunosuppression $(75,76)$.

This concept can be translated to fetal interventions in the form of in-utero hematopoetic stem cell transplants (IUHCT). As this is done before the complete development of fetal T-cells, these stem cells are processed as "self" which in turn leads to tolerance of the donor antigen (77). The main barrier to the success of this therapy is successful engraftment of the stem cells; in humans, IUHCT has only been successful in the management of X-linked Severe Combined Immunodeficiency $(78,79)$. The main limitation of its use in this disease is the survival advantage of donor cells and the outcomes are similar to postnatal transplantation (80). As our understanding of this treatment has improved (fetal microenvironment, barriers to engraftment, appropriate donor cell sources and optimal injection timing and technique), there is renewed hope that the use of IUHCT can be progressed into several disease states (81). For allograft organ transplantation, this has the potential to create an immunologically matched donor for each fetus (most likely a parent). This chimerism would then allow allograft function without the need for post-natal myeloablation, stem cell transplantation and long-term immunosuppression (81).

Outside of allograft transplants, an attempt at growing new kidneys from reprogrammed pluripotent stem cells (PSCs) has been made (82). There has been some progress at forcing these PSCs to differentiate into renal cell types as well as kidney organoids with glomerular and tubular components. However, there are many hurdles that need to be overcome including safety, technical manufacturing and complete renal anatomic organisation. Subsequently, the reality of this entering clinical practice will require significant more innovation and therefore time (82).

The advancement of bioengineering has brought the development of the renal assist device (RAD) (83). This is a hollow-fiber standard hemofilter seeded with tubule renal cells that was used in addition to continuous RRT in the support of renal function. From this platform, the implantable RAD (iRAD) was developed, which is a small $\left(0.1 \mathrm{~m}^{2}\right)$ device designed to act as an artificial kidney (84). This device consists of two chambers; the first of which acts as a hemofilter to remove toxins, excess water, and salts. The second chamber is seeded with renal tubule cells and will selectively reabsorb water and salts, also allowing the excretion of toxins $(85,86)$. This device was scheduled to enter clinical trials in 2017 and the results from this are awaited.

These technologies are still under development but hold excitement for the future of renal replacement. It is hoped that with successful implementation of these innovations, patients with a disease thought to be lethal have a chance at living a full life.

\section{Conclusions}

Interventions such as vesico-amniotic shunting and fetal cystoscopy have been available for patients with LUTO with oligo- or anhydramnios with some success. However, the data on these is sparse, and the PLUTO trial was not able to provide definitive answers. The prognosis for patients with EPRA has been poor with all dying in the neonatal period without fetal therapy. Fatality is primarily due to severe pulmonary hypoplasia secondary to 
anhydramnios before 22 weeks GA caused by severe renal anomalies that either inhibit urine production or block urine output. The current RAFT trial focuses on the use of serial amnioinfusions to restore amniotic fluid volume and rescue lung development to reduce the incidence of pulmonary hypoplasia in these patients. The hope is to allow them to progress beyond the neonatal period and utilise RRT for their ESRD.

The field is advancing and there is optimism that outcomes may be improved in conditions that were thought to be fatal. The difficulties in performing highquality trials in fetal interventions remain, and it is hoped that through collaboration we can advance evidence-based treatment of this incredibly vulnerable patient population. As technology develops, we hope there will be introduction of further therapies that can be used in this population to allow their prognosis to advance beyond neonatal survival with a realistic hope of kidney transplant to patients with essentially normal lungs and kidney function without immunosuppression.

\section{Acknowledgments}

Funding: None.

\section{Footnote}

Provenance and Peer Review: This article was commissioned by the editorial office, Translational Pediatrics for the series "Fetal Surgery". The article has undergone external peer review.

Reporting Checklist: The authors have completed the Narrative Review reporting checklist. Available at http:// dx.doi.org/10.21037/tp-2020-fs-05

Conflicts of Interest: All authors have completed the ICMJE uniform disclosure form (available at http://dx.doi. org/10.21037/tp-2020-fs-05). The series "Fetal Surgery" was commissioned by the editorial office without any funding or sponsorship. Dr. Eric Jelin served as the unpaid Guest Editor of the series. The authors have no other conflicts of interest to declare.

Ethical Statement: The authors are accountable for all aspects of the work in ensuring that questions related to the accuracy or integrity of any part of the work are appropriately investigated and resolved.
Open Access Statement: This is an Open Access article distributed in accordance with the Creative Commons Attribution-NonCommercial-NoDerivs 4.0 International License (CC BY-NC-ND 4.0), which permits the noncommercial replication and distribution of the article with the strict proviso that no changes or edits are made and the original work is properly cited (including links to both the formal publication through the relevant DOI and the license). See: https://creativecommons.org/licenses/by-nc-nd/4.0/.

\section{References}

1. Grandjean H, Larroque D, Levi S. The performance of routine ultrasonographic screening of pregnancies in the Eurofetus Study. Am J Obstet Gynecol 1999;181:446-54.

2. Elder JS. Antenatal hydronephrosis. Fetal and neonatal management. Pediatr Clin North Am 1997;44:1299-321.

3. Jelin AC, Sagaser KG, Forster KR, et al. Etiology and management of early pregnancy renal anhydramnios: Is there a place for serial amnioinfusions? Prenat Diagn 2020;40:528-37.

4. Balasundaram M, Chock VY, Wu HY, et al. Predictors of poor neonatal outcomes in prenatally diagnosed multicystic dysplastic kidney disease. J Perinatol 2018;38:658-64.

5. Hislop A, Hey E, Reid L. The lungs in congenital bilateral renal agenesis and dysplasia. Arch Dis Child 1979;54:32-8.

6. Ruano R, Safdar A, Au J, et al. Defining and predicting 'intrauterine fetal renal failure' in congenital lower urinary tract obstruction. Pediatr Nephrol 2016;31:605-12.

7. Bhide A, Sairam S, Farrugia MK, et al. The sensitivity of antenatal ultrasound for predicting renal tract surgery in early childhood. Ultrasound Obstet Gynecol 2005;25:489-92.

8. Haeri S. Fetal Lower Urinary Tract Obstruction (LUTO): a practical review for providers. Matern Health Neonatol Perinatol 2015;1:26.

9. Glick PL, Harrison MR, Golbus MS, et al. Management of the fetus with congenital hydronephrosis II: Prognostic criteria and selection for treatment. J Pediatr Surg 1985;20:376-87.

10. Vikraman SK, Chandra V, Balakrishnan B, et al. Impact of antepartum diagnostic amnioinfusion on targeted ultrasound imaging of pregnancies presenting with severe oligo- and anhydramnios: An analysis of 61 cases. Eur J Obstet Gynecol Reprod Biol 2017;212:96-100.

11. Lissauer D, Morris RK, Kilby MD. Fetal lower urinary tract obstruction. Semin Fetal Neonatal Med 2007;12:464-70. 
12. Ruano R. Fetal surgery for severe lower urinary tract obstruction. Prenat Diagn 2011;31:667-74.

13. Heikkilä J, Holmberg C, Kyllonen L, et al. Long-term risk of end stage renal disease in patients with posterior urethral valves. J Urol 2011;186:2392-6.

14. Sarhan O, Zaccaria I, Macher MA, et al. Long-term outcome of prenatally detected posterior urethral valves: single center study of 65 cases managed by primary valve ablation. J Urol 2008;179:307-12; discussion 312-3.

15. Robyr R, Benachi A, Daikha-Dahmane F, et al. Correlation between ultrasound and anatomical findings in fetuses with lower urinary tract obstruction in the first half of pregnancy. Ultrasound Obstet Gynecol 2005;25:478-82.

16. Anumba DO, Scott JE, Plant ND, et al. Diagnosis and outcome of fetal lower urinary tract obstruction in the northern region of England. Prenat Diagn 2005;25:7-13.

17. Ruano R, Sananes N, Sangi-Haghpeykar H, et al. Fetal intervention for severe lower urinary tract obstruction: a multicenter case-control study comparing fetal cystoscopy with vesicoamniotic shunting. Ultrasound Obstet Gynecol 2015;45:452-8.

18. Freedman AL, Johnson MP, Smith CA, et al. Longterm outcome in children after antenatal intervention for obstructive uropathies. Lancet 1999;354:374-7.

19. Liao AW, Sebire NJ, Geerts L, et al. Megacystis at 1014 weeks of gestation: chromosomal defects and outcome according to bladder length. Ultrasound Obstet Gynecol 2003;21:338-41.

20. Bernardes LS, Aksnes G, Saada J, et al. Keyhole sign: how specific is it for the diagnosis of posterior urethral valves? Ultrasound Obstet Gynecol 2009;34:419-23.

21. Miller OF, Lashley DB, McAleer IM, et al. Diagnosis of urethral obstruction with prenatal magnetic resonance imaging. J Urol 2002;168:1158-9.

22. Ruano R, Duarte S, Bunduki V, et al. Fetal cystoscopy for severe lower urinary tract obstruction--initial experience of a single center. Prenat Diagn 2010;30:30-9.

23. Nicolini U, Spelzini F. Invasive assessment of fetal renal abnormalities: urinalysis, fetal blood sampling and biopsy. Prenat Diagn 2001;21:964-9.

24. O'Hare EM, Jelin AC, Miller JL, et al. Amnioinfusions to Treat Early Onset Anhydramnios Caused by Renal Anomalies: Background and Rationale for the Renal Anhydramnios Fetal Therapy Trial. Fetal Diagn Ther 2019;45:365-72.

25. Evans MI, Sacks AJ, Johnson MP, et al. Sequential invasive assessment of fetal renal function and the intrauterine treatment of fetal obstructive uropathies. Obstet Gynecol
1991;77:545-50.

26. Carroll SG, Soothill PW, Tizard J, et al. Vesicocentesis at 10-14 weeks of gestation for treatment of fetal megacystis. Ultrasound Obstet Gynecol 2001;18:366-70.

27. Jouannic JM, Hyett JA, Pandya PP, et al. Perinatal outcome in fetuses with megacystis in the first half of pregnancy. Prenat Diagn 2003;23:340-4.

28. Favre R, Kohler M, Gasser B, et al. Early fetal megacystis between 11 and 15 weeks of gestation. Ultrasound Obstet Gynecol 1999;14:402-6.

29. Clark TJ, Martin WL, Divakaran TG, et al. Prenatal bladder drainage in the management of fetal lower urinary tract obstruction: a systematic review and meta-analysis. Obstet Gynecol 2003;102:367-82.

30. Morris RK, Malin GL, Khan KS, et al. Systematic review of the effectiveness of antenatal intervention for the treatment of congenital lower urinary tract obstruction. BJOG 2010;117:382-90.

31. Pluto Collaborative Study Group, Kilby M, Khan K, et al. PLUTO trial protocol: percutaneous shunting for lower urinary tract obstruction randomised controlled trial. BJOG 2007;114:904-5, e1-4.

32. Van Mieghem T, Ryan G. The PLUTO trial: a missed opportunity. Lancet 2013;382:1471-3.

33. Morris RK, Malin GL, Quinlan-Jones E, et al. Percutaneous vesicoamniotic shunting versus conservative management for fetal lower urinary tract obstruction (PLUTO): a randomised trial. Lancet 2013;382:1496-506.

34. Welsh A, Agarwal S, Kumar S, et al. Fetal cystoscopy in the management of fetal obstructive uropathy: experience in a single European centre. Prenat Diagn 2003;23:1033-41.

35. Holmes N, Harrison MR, Baskin LS. Fetal surgery for posterior urethral valves: long-term postnatal outcomes. Pediatrics 2001;108:E7.

36. Sananes N, Cruz-Martinez R, Favre R, et al. Two-year outcomes after diagnostic and therapeutic fetal cystoscopy for lower urinary tract obstruction. Prenat Diagn 2016;36:297-303.

37. Cameron D, Lupton BA, Farquharson D, et al. Amnioinfusions in renal agenesis. Obstet Gynecol 1994;83:872-6.

38. Majmudar A, Cohen HL. "Lying-Down" Adrenal Sign: There Are Exceptions to the Rule Among Fetuses and Neonates. J Ultrasound Med 2017;36:2599-603.

39. Thomas AN, McCullough LB, Chervenak FA, et al. Evidence-based, ethically justified counseling for fetal bilateral renal agenesis. J Perinat Med 2017;45:585-94. 
40. Weinstein A, Goodman TR, Iragorri S. Simple multicystic dysplastic kidney disease: end points for subspecialty follow-up. Pediatr Nephrol 2008;23:111-6.

41. Wilson PD. Polycystic kidney disease. N Engl J Med 2004;350:151-64.

42. Guay-Woodford LM. Autosomal recessive polycystic kidney disease: the prototype of the hepato-renal fibrocystic diseases. J Pediatr Genet 2014;3:89-101.

43. DiFiore JW, Wilson JM. Lung Liquid, Fetal lung growth and congenital diaphragmatic hernia. Pediatr Surg Int 1995;10:2-9.

44. Dickson KA, Harding R. Restoration of lung liquid volume following its acute alteration in fetal sheep. $\mathrm{J}$ Physiol 1987;385:531-43.

45. Alcorn D, Adamson TM, Lambert TF, et al. Morphological effects of chronic tracheal ligation and drainage in the fetal lamb lung. J Anat 1977;123:649-60.

46. Hooper SB, Harding R. Fetal lung liquid: a major determinant of the growth and functional development of the fetal lung. Clin Exp Pharmacol Physiol 1995;22:235-47.

47. Harding R, Sigger JN, Wickham PJ, et al. The regulation of flow of pulmonary fluid in fetal sheep. Respir Physiol 1984;57:47-59.

48. Adzick NS, Harrison MR, Glick PL, et al. Experimental pulmonary hypoplasia and oligohydramnios: relative contributions of lung fluid and fetal breathing movements. J Pediatr Surg 1984;19:658-65.

49. Kitterman JA. The effects of mechanical forces on fetal lung growth. Clin Perinatol 1996;23:727-40.

50. Wigglesworth JS, Desai R, Hislop AA. Fetal lung growth in congenital laryngeal atresia. Pediatr Pathol 1987;7:515-25.

51. Potter EL, Bohlender GP. Intrauterine respiration in relation to the development of the fetal lung. Am J Obstet Gynecol 1941;42:14-22.

52. Carmel JA, Friedman F, Adams FH. Fetal Tracheal Ligation and Lung Development. Am J Dis Child 1965;109:452-6.

53. Lanman JT, Schaffer A, Herod L, et al. Distensibility of the fetal lung with fluid in sheep. Pedatr Res 1971;5:586-90.

54. Jost PA, Policard A. Contribution experimentale a l'etude du developpement prenatal du poumon chez le lapin. Arch Anat Microscop 1948;37:323-32.

55. Van der Veeken L, Russo FM, De Catte L, et al. Fetoscopic endoluminal tracheal occlusion and reestablishment of fetal airways for congenital diaphragmatic hernia. Gynecol Surg 2018;15:9.
56. Moxey-Mims M, Raju TNK. Anhydramnios in the Setting of Renal Malformations: The National Institutes of Health Workshop Summary. Obstet Gynecol 2018;131:1069-79.

57. Perez-Brayfield MR, Kirsch AJ, Smith EA. Monoamniotic twin discordant for bilateral renal agenesis with normal pulmonary function. Urology 2004;64:589.

58. Bienstock JL, Birsner ML, Coleman F, Hueppchen NA. Successful in utero intervention for bilateral renal agenesis. Obstet Gynecol 2014;124:413-5.

59. Whittaker N, Leonardi M. Five-Month Survival of Neonate After Serial Amnioinfusions for Fetal Bilateral Renal Agenesis [18D]. Obstet Gynecol 2016;127:39S.

60. Carey WA, Talley LI, Sehring SA, et al. Outcomes of dialysis initiated during the neonatal period for treatment of end-stage renal disease: a North American Pediatric Renal Trials and Collaborative Studies special analysis. Pediatrics 2007;119:e468-73.

61. Lantos JD, Warady BA. The evolving ethics of infant dialysis. Pediatr Nephrol 2013;28:1943-7.

62. Rees L. Renal replacement therapies in neonates: issues and ethics. Semin Fetal Neonatal Med 2017;22:104-8.

63. Porat S, Amsalem H, Shah PS, et al. Transabdominal amnioinfusion for preterm premature rupture of membranes: a systematic review and metaanalysis of randomized and observational studies. Am J Obstet Gynecol 2012;207:393.e1-393.11.

64. Roberts D, Vause S, Martin W, et al. Amnioinfusion in very early preterm prelabor rupture of membranes (AMIPROM): pregnancy, neonatal and maternal outcomes in a randomized controlled pilot study. Ultrasound Obstet Gynecol 2014;43:490-9.

65. Werner EF, Hauspurg A, Bienstock JL. In-utero treatment of bilateral renal agenesis: a threshold analysis of possible cost effectiveness. Obstet Gynecol Int J 2015;2:3-85.

66. Sugarman J, Anderson J, Baschat AA, et al. Ethical Considerations Concerning Amnioinfusions for Treating Fetal Bilateral Renal Agenesis. Obstet Gynecol 2018;131:130-4.

67. Malin G, Tonks AM, Morris RK, et al. Congenital lower urinary tract obstruction: a population-based epidemiological study. BJOG 2012;119:1455-64.

68. De Santis M, Scavo M, Noia G, et al. Transabdominal amnioinfusion treatment of severe oligohydramnios in preterm premature rupture of membranes at less than 26 gestational weeks. Fetal Diagn Ther 2003;18:412-7.

69. Tchirikov M, Steetskamp J, Hohmann M, et al. Longterm amnioinfusion through a subcutaneously implanted amniotic fluid replacement port system for treatment of 
PPROM in humans. Eur J Obstet Gynecol Reprod Biol 2010;152:30-3.

70. Turgut A, Katar S, Sak ME, et al. Continuous amnioinfusion via an epidural catheter following spontaneous membrane rupture: A case report. J Turk Ger Gynecol Assoc 2013;14:238-41.

71. Polzin WJ, Lim FY, Habli M, et al. Use of an Amnioport to Maintain Amniotic Fluid Volume in Fetuses with Oligohydramnios Secondary to Lower Urinary Tract Obstruction or Fetal Renal Anomalies. Fetal Diagn Ther 2017;41:51-7.

72. Feng S, Zhuang Y, Liu H, et al. Long-term survival in a recipient of kidney transplant without maintenance immunosuppression: A case report. Exp Thera Med 2018;16:360-3.

73. Sykes M. Mixed chimerism and transplant tolerance. Immunity 2001;14:417-24.

74. Sachs DH, Kawai T, Sykes M. Induction of tolerance through mixed chimerism. Cold Spring Harb Perspect Med 2014;4:a015529.

75. Scandling JD, Busque S, Dejbakhsh-Jones S, et al. Tolerance and withdrawal of immunosuppressive drugs in patients given kidney and hematopoietic cell transplants. Am J Transplant 2012;12:1133-45.

76. Scandling JD, Busque S, Dejbakhsh-Jones S, et al. Tolerance and chimerism after renal and hematopoieticcell transplantation. N Engl J Med 2008;358:362-8.

77. Nijagal A, Derderian C, Le T, et al. Direct and indirect antigen presentation lead to deletion of donor-specific $\mathrm{T}$ cells after in utero hematopoietic cell transplantation in mice. Blood 2013;121:4595-602.

Cite this article as: Irfan A, O'Hare E, Jelin E. Fetal interventions for congenital renal anomalies. Transl Pediatr 2021;10(5):1506-1517. doi: 10.21037/tp-2020-fs-05
78. Westgren M, Ringden O, Bartmann P, et al. Prenatal T-cell reconstitution after in utero transplantation with fetal liver cells in a patient with $\mathrm{X}$-linked severe combined immunodeficiency. Am J Obstet Gynecol 2002;187:475-82.

79. Flake AW, Roncarolo MG, Puck JM, et al. Treatment of $\mathrm{X}$-linked severe combined immunodeficiency by in utero transplantation of paternal bone marrow. N Engl J Med 1996;335:1806-10.

80. Buckley RH, Schiff SE, Schiff RI, et al. Hematopoietic stem-cell transplantation for the treatment of severe combined immunodeficiency. $\mathrm{N}$ Engl J Med 1999;340:508-16.

81. Vrecenak JD, Flake AW. In utero hematopoietic cell transplantation--recent progress and the potential for clinical application. Cytotherapy 2013;15:525-35.

82. Volovelsky O, Kopan R. Making new kidneys: On the road from science fiction to science fact. Curr Opin Organ Transplant 2016;21:574-80.

83. Humes HD, Buffington DA, MacKay SM, et al. Replacement of renal function in uremic animals with a tissue-engineered kidney. Nat Biotechnol 1999;17:451-5.

84. Roy S, Goldman K, Marchant R, et al. Implanted renal replacement for end-stage renal disease. Panminerva Med 2011;53:155-66.

85. Fissell WH, Dubnisheva A, Eldridge AN, et al. HighPerformance Silicon Nanopore Hemofiltration Membranes. J Memb Sci 2009;326:58-63.

86. Fissell WH, Roy $\mathrm{S}$. The implantable artificial kidney. Semin Dial 2009;22:665-70. 